\title{
The Domain of International Business and the AIB
}

Simon Collinson, University of Birmingham, UK

Yves Doz, INSEAD, France

Tatiana Kostova, University of South Carolina, USA

Peter Liesch, University of Queensland, Australia

Kendall Roth, University of South Carolina, USA

\section{AIB INSIGHTS HAS EVOLVED to feature the full range of IB scholars'} interests, from teaching curriculum issues to current affairs that have a bearing on our research agenda, to reporting on the wide variety of research we undertake. The very scope of this journal raises the question: what is the domain of international business?

At the Nagoya AIB Conference in June 2011, following an ambitious initiative by AIB President Mary Ann Von Glinow and the AIB Executive, a set of working groups were created to examine some of the challenges facing our organisation. One of these was the AIB Strategy Working Group on the Domain of IB and the AIB. ${ }^{1}$ The following is based around the report of this group and subsequent discussions of the AIB Board.

The Working Group focused on three distinctive areas of the IB domain, led by the following three broad questions:

1. What distinctive, distinguishing characteristics and features, what boundaries and benchmarks define and differentiate the field of international business (IB)?

2. What would comprise a legitimate curriculum for the teaching of IB globally? What would be the criteria and benchmarks for accreditation of any IB teaching programme?

3. Who are the main stakeholders and interest groups that we are (or should be) connected to?

For each of these we aimed to:

a. Capture some kind of consensus from past analysis and discussions

b. Identify where new challenges might prompt a revision of the IB domain

c. Outline any implications for the scope and activities of the AIB

\section{What Distinctive, Distinguishing Characteristics and Features, What Boundaries and Benchmarks Define and Differentiate the Field of IB?}

As predicted this proved to be the most challenging question, given it is both open-ended and strongly contested. It has, however, been the

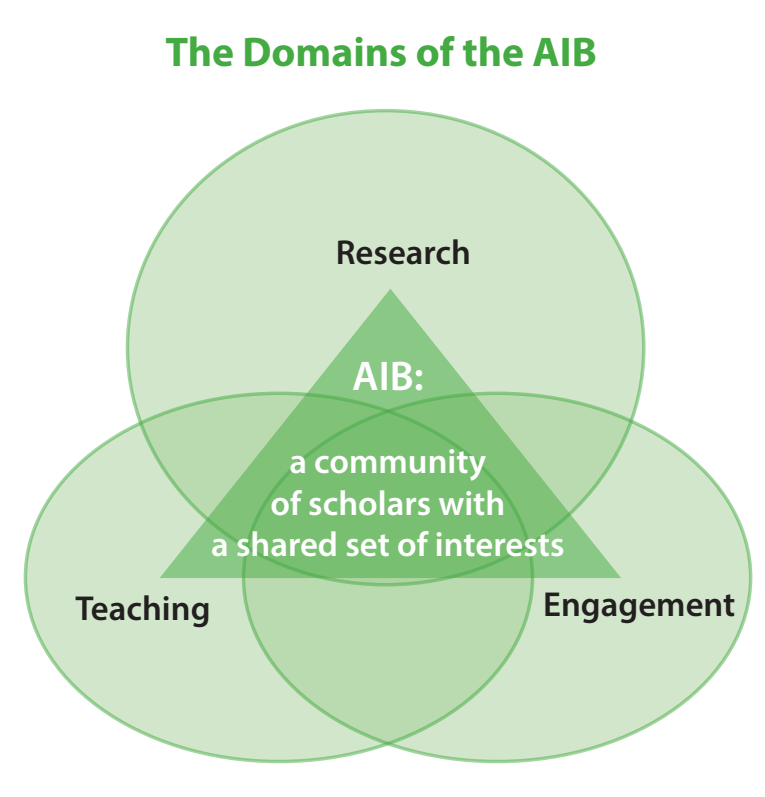

subject of many articles and AIB panels in the past. (See other definitions and characterisations in the articles listed in the references at the end of this report. Note, though, that this list is not only incomplete, it is not particularly representative.) Whilst there is no general agreement on the defining characteristics and boundaries of the domain, our discussions led us to the view that many of the past definitions have become outmoded. The ongoing debate needs to prioritise a number of contemporary influences, as does any reshaping of the AIB remit.

The most recent JIBS statement of editorial policy, citing six areas of the field, does take a more contemporary and eclectic approach and would be our preferred benchmark. However: (1) it is still implicitly or explicitly closed to a number of areas of research (e.g., single-country studies), and; (2) there is still a gap between its aspirational aims for the field (via topic-specific research papers) and our currently realised scope and the activities of the AIB.

At the heart of the field, the boundaries of the MNE have changed substantially since early definitions. Past distinctions between firm and market and distinctions between public and private, for example, have become blurred. A greater variety of organisational forms and a greater continued on page 4 


\section{continued from page 3}

complexity of interrelationships now constitute international organisational life. These and other phenomena present challenges to the theoretical boundary conditions and assumptions of the past.

Rather than expand on this we chose to focus on the contested periphery of the field in three specific areas: disciplinary legitimacy and interdisciplinarity; universality; relevance and user engagement. These are connected to the remaining two topics under our stated remit: teaching curricula and stakeholders.

\section{Disciplinary Legitimacy and Interdisciplinarity}

IB scholars have reflected for some time on the legitimacy of the field in relation to more established and accepted disciplines. These include economics, geography, political science, sociology, anthropology, and other disciplinary areas referred to in association with IB.

We support an emerging view which advocates the development of IB as both a distinctive and differentiated field of studies in its own right and one which helps to bridge, integrate, and link other disciplines and/ or sub-disciplines. IB research can provide greater explanatory power through this integrative role, but it also needs independent credibility. This recognises the IB field as a body of knowledge, a set of empirical data, analytical frameworks, tools, and techniques that add value in either manifestation, alone and in combination with other disciplines. This added value should be judged in terms of the improved robustness of explanations of the international dimension than individual subjects achieve on their own.

In addition, by applying other disciplines to the IB and MNE contexts, IB can contribute back to those fields by challenging their assumptions and boundary conditions and modifying and expanding their main theories. To some extent, despite having the potential to contribute, IB has been traditionally overlooked by other disciplines. The phenomenon of asymmetric referencing (us citing them, but them not citing us) provides some evidence to show we are rather peripheral as a field of enquiry.

Therefore the same rule-of-thumb should apply in relation to our own "core theories." Where more robust explanations can be achieved through disciplinary integration this should be encouraged. Dogmatism is arguably retarding the evolution of our field and those of other disciplines.

Many of these points have been made in discussions elsewhere. Our main proposition is that the IB field should encompass both, rather than one or the other of the above domains. It should be proactively developed as both a distinctive field of studies in its own right and one which both incorporates and informs other disciplines.

If this is accepted by the leadership and membership of AIB, it has implications for our strategy and activities, in terms of our interface and interaction with academics and academic organisations in other disciplines and subject areas.

\section{Recommendations}

We propose that the AIB:

- More proactively encourage acceptance of a broader range of papers at AIB conferences and journals and foster the participation and presence of under-represented disciplinary views. Such efforts might usefully be focused thematically, around different phenomena/issues over time.

- Examine the viability of disciplinary subgroups within AIB (economics, geography, political science, sociology, anthropology), which would be able to engage with parallel groups outside of the AIB. At the same time (however contrary this appears) it seems necessary to facilitate dialogue across disciplinary subgroups.

- Look to connect more frequently with other academic organisations to develop the interface and integrative potential between our subject fields.

- Emphasise the need to not only apply existing theories from other disciplines, but in so doing, to extend and modify these theories in light of the conceptually distinctive nature of the IB context. This may entail a more deliberate and proactive outreach agenda, including the promotion of joint conferences and targeted journal special issues.

\section{Universality}

A central theme in IB studies - as in all scientific and social science research - is the search for "universal truths" or general principles. This sits alongside a second IB theme, that locations or places vary and context matters. As part of the question of the domain of IB we need to also ask how "universal" are our "universal theories," and what are the scientific processes by which universals are discovered?

These are even more relevant questions today, given the rise of alternative forms of capitalism, the knowledge economy, and other empirical shifts. To some extent, these challenge accepted theories that have largely evolved to explain Anglo-American or Western firms, institutions, and national systems, but they fail to fully explain the empirical realities of other contexts. Similar issues exist at the behavioural and cognition levels. This has, in part, led to recent calls for "deeply contextualized" or indigenous inquiry as a source for more robust or novel theory building. Such efforts dominantly result in localized or context-specific theory. However, universals may still emerge by synthesizing and abstracting across context-specific results, rather than imposing such expectations a priori. And more important from an IB perspective, perhaps the most advanced understanding of a given phenomenon will emerge as we embrace universal forms of explanation alongside explanations that are local in character.

In parallel with the empirical realities referred to above, the actual and potential membership of the AIB is expanding to encompass scholars from different intellectual contexts. These should rightly be the source 
of new influences over the definition of these universalities and the IB domain as we define it. Currently we see a tendency to "shoehorn" alternative perspectives into an Anglo-American dominated view of legitimate universalities.

This debate also encompasses some common areas of constructive tension within our scholarly community, including, for example:

- The relative importance of qualitative and quantitative approaches

- Whether emerging economies merit new IB theories

- The legitimacy of single-country studies

- The centrality of the MNE (or private firms per se) as the core unit of analysis

\section{Recommendations}

Despite the importance of this to the domain definition of the IB field, it is not clear what specific steps can be taken to improve our openness to this kind of change.

One idea is for the AIB to facilitate, perhaps at the annual conference, large-scale comparative international research programs involving the membership. Another is for AIB to support indigenous inquiry that spans across the "intellectual borders" that surround our concepts and theoretical logic.

There are links to both relevance and user engagement, given that failure to adapt our theoretical foundations threatens to undermine our relevance and legitimacy. There are also obvious links via this to the stakeholder question below.

\section{Relevance and User Engagement}

Concerns that the IB research agenda could be "running out of steam" have been examined by many, including Liesch et al. (2011), who map the evolution of field from a focus on macro-environmental issues to a more recent focus on micro-economic, firm-level issues. They observe that the field has established a "justifiable claim for relevance, participating actively in the interdisciplinary exchange of ideas."

In a paper published in JIBS in 2004, Buckley and Ghauri argue that international business research succeeds when it responds to the need to answer a series of what they call "big questions" in the world economy. They proceed to say that such a "big question" is the changing strategy of multinational enterprises (MNEs) and the way it affects globalisation and its geographical expression through the location of the activities of MNES.

We would extend the principle well beyond this (rather mainstream IB) example to encompass more of the "grand challenges" that face us all. These could extend from climate change or poverty alleviation to corporate ethics or the "crisis of (Western) capitalism"; however, the scope will not be determined by issuing an agreed list, it will evolve from the focus and actions of engaged researchers.
These are also the kinds of problems that are likely to benefit from a more interdisciplinary approach and a questioning of accepted universalities. Moreover, robust solutions are likely to be found through engaged scholarship which includes research users (practitioners and policymakers) at an early stage in the research (not just as targets for the distribution of semi-relevant findings).

Currently there are a number of institutional constraints that limit IB researcher's ability to focus on the 'big questions' and fully engage research users. These vary by country and context and most are beyond the scope of the AIB. But there are some steps the AIB could take to prompt a shift in the IB domain to meet the above challenge (see below and in Section 3 related to stakeholders). The alternative may be for less credible research organisations to take the lead in these highly prominent areas and arenas.

\section{Recommendations}

We propose that the AIB:

- Develop more ways of engaging with particular stakeholders at the annual conference and beyond. The existing links with UNCTAD and the involvement of IB scholars in the development of annual WIR may provide useful lessons to build on.

- More specifically engage in reaching out to policy makers and practitioners, targeting for example government agencies and large enterprises in emerging markets. Develop collaborative initiatives with them that are beneficial for both, researchers- to gain new insights based on studying those contexts, and countries-providing knowledge to those constituents.

- There may well be some overlap with the recommendations of the "outreach" working group in terms of concrete proposals for improving engagement with research users.

\section{What Would Comprise a Legitimate Curriculum for the Teaching of IB Globally? What Would Be the Criteria and Benchmarks for Accreditation of Any IB Teaching Pro- gramme?}

Our main conclusion in response to this domain question is that the AIB should develop its role in this area and actively seek to become an organisation that oversees the accreditation of international business and management programmes globally. This could also connect with an advocacy role in relation to other academic and teaching-related organisations (AACSB, EFMD, EQUIS, ABS, and so on; see Section 3 below on stakeholders). The role could also extend to providing advice on, even lobbying for, a greater level of international content in functional courses and the internationalisation of programs, for example.

However, no single curriculum but rather a defined range of topic arcontinued on page 6 
continued from page 5

eas, theoretical approaches, analytical frameworks, and tools should be compiled. This would provide the basis for both accreditation purposes and for providing input and advice to faculty and schools that seek guidance on curricula matters. The range of subjects, theories, frameworks, and tools included within an "AIB-approved" curriculum should be developed through further consultation. This should be continually open to revision in line with the changing empirical realities, the needs of teaching faculty and users (see Section 3 below).

We expect that several models will emerge from such an exercisewith topic options, assessment modes and accreditation criteria varying depending on the target group of students and the teaching context. Appendix 1 provides an obvious starting point for such as exercise.

More specifically we advocate that an agreed subset of existing teaching resources, including JIBS (and perhaps other leading journals) alongside a selected number of established IB textbooks, should be agreed upon as the foundation for an "AIB-approved" IB pedagogy.

\section{Recommendations}

Assuming there is wider support from the membership for the AIB to extend its activities into this area (which should be confirmed) we propose the AIB establish a working group to develop this further. Three related sets of actions need to be taken:

- Define and agree on the core "AIB-approved" curriculum,

- Establish criteria, benchmarks, and a process for managing accreditation of IB teaching programmes (if demand exists),

- Examine opportunities and specific institutions to approach to promote AIB-approved teaching programmes as part of the AIB outreach function.

At a subsequent stage, AIB should engage with the relevant accreditation organisations such as AACSB, EFMD, EQUIS and ABS, to develop any necessary affiliation or partnership.

\section{The Domains of the AIB}

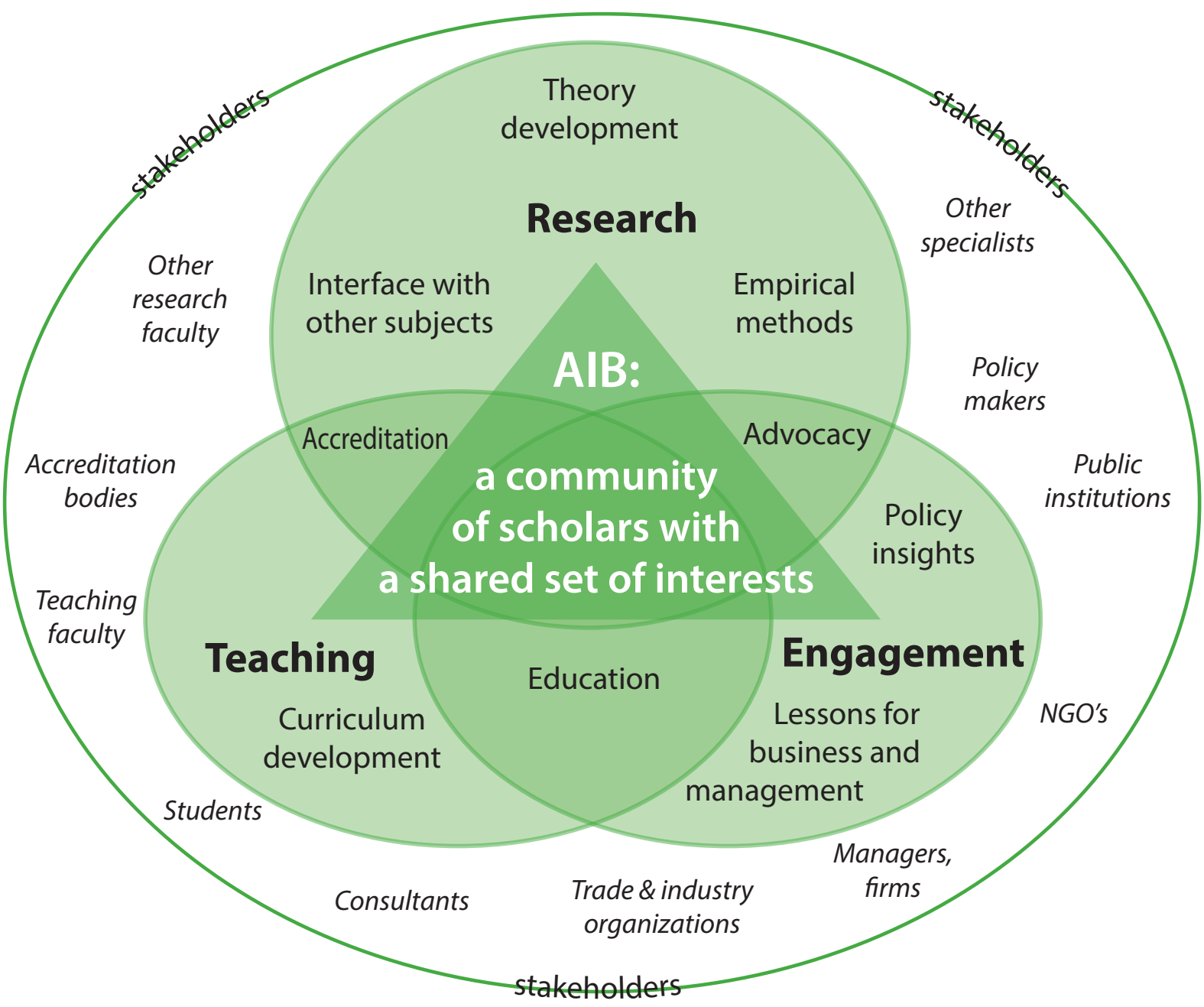




\section{Who Are the Main Stakeholders and Interest Groups That We Are (or Should Be) Connected to?}

The figure below captures elements of the above discussion and lists some obvious stakeholders in relation to AIB.

Our membership, encompassing research-active faculty that regularly attend AIB events, is the primary stakeholder group. Other research and teaching faculty, researchers, and students in the IB area and beyond are a secondary constituency.

AIB members are individually and institutionally linked more or less strongly to a range of stakeholders. In simple aggregate terms these also comprise the wider latent population of AIB stakeholders. The simple dilemma, however, is that most of these are positioned at the national level, despite having concerns that may be more or less international. This applies to the three generic groups outlined in the above figure: other, non-IB faculty, researchers, and teachers; government-related policy makers, NGOs, charities, and advisory groups; private sector practitioners in multinational (or would-be multinational) enterprises.

Given the above dilemma it seems to make sense for AIB Chapters at the regional or country level to play a role in specifying and connecting with appropriate stakeholders at their level. This still leaves a central role for AIB to identify and connect with supra-national stakeholders. This means targeting the major MNEs and well-known transnational NGOs. Obvious candidates are: the World Economic Forum, the World Bank and the IMF, OECD, IMF, WTO, and possibly regional trade and economic organisations such as the EU and APEC.

The AIB's evolving relationship with UNCTAD perhaps provides some lessons on how links with stakeholders could be developed and this role extended.

The key "hook" in terms of potential areas of mutual interest partly relates to the "big questions" point above. Raising the profile of the AIB and building our credibility as the pre-eminent group of IB scholars can only be done by taking more proactive steps to connect with the challenges and agendas of high-profile policy makers and corporate leaders. This is also a test of our own superior ability to add valuable insights through our expertise as IB scholars.

Finally, should the membership support this remit extension, a parallel effort should be made in relation to establishing the AIB as the foremost accreditor of IB teaching programs through engagement with relevant stakeholders (see Section 2 above).

\section{Recommendations}

We propose that the AIB:

- Develop specific ways to bring research insights on key issues of the day to the attention of policymakers, practitioners and the public. This would inevitably involve a degree of proactive development and marketing of press-releases. "Pushing" feeds via vari- ous online professional and social network media would be part of this effort.

- Examine the possibilities of establishing a new category of associate membership to bring non-academics into the AIB.

- Explore seriously a change in the annual conference to comprise sessions that not just include abovementioned stakeholders but are explicitly led by them and their agendas, presenting tangible problems as challenges for IB scholars.

- Look into the options for developing an advisory role with government organisations and NGOs through the AIB outreach function.

\section{Conclusion}

In conclusion, the AIB should aim to further legitimise IB and advocate $\mathrm{IB}$ as a field of study. In the process of domain definition we should be looking for opportunities to extend our domain, to encompass the new realities of our field, theoretically, empirically, and institutionally. The ambition is to realise the full potential of our superior insights into the influences and impacts of international business through a stronger role in advocacy via both teaching and stakeholder engagement.

This requires:

(1) Clarifying the theoretical, analytical, and empirical domain of AIB as a field of study;

(2) Defining and accrediting a standard set of IB teaching curricula, based on (1) above;

(3) Identifying and proactively engaging with research users and stakeholders to bring the additional insights and problem-solving potential of the IB field to bear on the concerns of people beyond our immediate peer group.

Finally, to encompass the principal ambitions outlined above, we propose a domain statement for the AIB.

\section{A Domain Statement for the AIB}

The Academy of International Business (AIB) is a global community of scholars and specialists interested in the real-world phenomena, problems, and puzzles that arise from, or relate to, the activities of firms and other organisations that cross national borders or are undertaken in more than one country, and the economic, social, and political consequences of these activities. They seek a better understanding of the problems and opportunities that these activities and consequences create, drawing upon the full suite of disciplines that informs the strategies, structures, and processes within firms, institutions, and other organisations, their locations, and the motivations and behaviours of people working for them. To deliver on its research purpose, the field of international business is multidisciplinary in

continued on page 8 
continued from page 7

scope, interdisciplinary in content, and methodologically pluralistic. Through scholarly publication, teaching, consultancy, and advocacy, the AIB community reaches a global constituency to improve the performance of internationally active firms and other institutions, and the well-being of people affected by their activities.

\section{References}

AlB Insights, Vol. 9, No. 1, 2009.

Boddewyn, J. J. 1999. The domain of international management. Journal of International Management, 5(1): 3-14.

Buckley, P. J. 2002. Is the international business research agenda running out of steam? Journal of International Business Studies, 33(2): 365-373.

Buckley, P. J., \& Lessard, D.R. 2005. Regaining the edge for international business research. Journal of International Business Studies, 36(6): 595-599.

Cantwell, J., \& Brannen, M. Y. 2010. Positioning JIBS as an interdisciplinary journal. Journal of International Business Studies, 42(1): 1-9.

Cheng, J., Henisz, W., Roth, K., \& Swaminathan, A. 2009. Advancing interdisciplinary research in the field of international business: Prospects, issues, and challenges. Journal of International Business Studies, 40: 1070-1074.

Dunning, J.H. 1989. The study of international business: A plea for a more interdisciplinary approach. Journal of International Business Studies, 20(3): 411-436.

Liesch, P. W., Hakanson, L., McGaughey, S. L., Middleton, S., \& Cretchley, J. 2011. The evolution of the international business field: A scientometric investigation of articles published in its premier journal. Scientometrics, 88(1): 17-42.

Rugman, A. M., \& Collinson, S. C. 2012. International Business (6th edn). London: FT Pearson.

Shenkar, O. 2004. One more time: International business in a global economy. Journal of International Business Studies, 35(2): 161171.

Toyne, B., \& Nigh, D. (Eds) 1999. International business: Institutions and the dissemination of knowledge. Columbia, SC: University of South Carolina Press.

Tsui, A. S. 2007. From homogenization to pluralism: International management research in the academy and beyond. Academy of Management Journal, 50(6): 1353-1364.

\section{Appendix: Generic Example of an International Business Curriculum}

This is an example list of topics taken from three leading IB textbooks (by Rugman \& Collinson, 2012; Daniels, Radebaugh \& Sullivan, 2011; Hill, 2010). Their contents are not dissimilar from most other IB textbook offerings. It is not meant to be comprehensive illustration, merely a starting point for development.

THE ENVIRONMENT OF INTERNATIONAL BUSINESS

Regional and global strategy

The multinational enterprise

The triad and international business

Global institutions and varieties of capitalism

Corporate ethics in the international business environment

INTERNATIONAL BUSINESS STRATEGIES

International politics and institutions

International culture

International trade and trade theory

Global patterns of foreign direct investment

International financial markets and institutions

Multinational strategy

Market entry, international alliances, and joint ventures

Organising strategy internationally

International corporate strategy and national competitiveness

International R\&D and innovation

International entrepreneurship and "born global" firms

FUNCTIONAL AREA STRATEGIES

International production strategy

International marketing strategy

International human resource management strategy

International political risk and negotiation strategy

International financial management

REGIONAL STRATEGIES

European Union

Japan

North America

Emerging economies

Brazil

Russia

India

China

\section{Endnotes}

1 Its members were: Simon Collinson (Chair), Yves Doz, Peter Liesch, Tatiana Kostova, and Kendall Roth. 
Simon Collinson is Dean of Birmingham Business School and Professor of International Business and Innovation at the University of Birmingham. He was previously at Henley Business School, University of Reading and Warwick Business School, where he held the post of Deputy Dean. Simon's current research is on collaborative innovation in China and he is a Visiting Professor at Zhejiang University in Hangzhou. He is also co-author of the FT / Pearson International Business (6th Ed.) textbook with Alan Rugman.

Yves Doz is the Solvay Chaired Professor of Technological Innovation at INSEAD. He received his Doctoral degree from Harvard University and he has taught at the Harvard Business School, Stanford's Graduate School of Business, Seoul National University, and Aoyama Gakuin University in Tokyo. He was President of the Academy of International Business in 2008-2010. His most recent research is featured in his new book, Managing Global Innovation, co-authored with Keeley Wilson, published in 2012 by Harvard Business Review Press.

Tatiana Kostova (Ph.D., University of Minnesota) is the Buck Mickel Chair and Professor of International Business at the University of South Carolina's Darla Moore School of Business. Her research is at the intersection of MNC management and organization theory and addresses questions of institutional and cultural embeddedness of MNCs, crossborder transfer of management practices, organizational legitimacy, and social capital in MNCs. She has served as AIB Vice President and is an AIB Fellow.

Peter Liesch is Professor of International Business in the UQ Business School at The University of Queensland, Australia. His current research interests include firm internationalisation processes and international business operations in their entirety. He is a Professional Member of the Economic Society of Australia, a Fellow of the Australian Institute of Management, and Vice-President (Administration) of the Academy of International Business.

Kendall Roth is Senior Associate Dean for International Programs and Partnerships at the Darla Moore School of Business, University of South Carolina. He holds the J. Willis Cantey Chair of International Business and Economics and is a Fellow of the Academy of International Business. He is a member of the editorial boards for the Journal of International Business Studies, Academy of Management Journal, Strategic Management Journal, and Global Strategy Journal. 